\title{
Fortifications et résidences des élites du haut Moyen Âge entre Loire et Garonne
}

\section{Luc Bourgeois}

\section{(2) OpenEdition Journals}

Édition électronique

URL : http://journals.openedition.org/adlfi/771

ISSN : 2114-0502

Éditeur

Ministère de la culture

Référence électronique

Luc Bourgeois, "Fortifications et résidences des élites du haut Moyen Âge entre Loire et Garonne », ADLFI. Archéologie de la France - Informations [En ligne], Poitou-Charentes, mis en ligne le 01 mars 2008, consulté le 19 avril 2019. URL : http://journals.openedition.org/adlfi/771

Ce document a été généré automatiquement le 19 avril 2019

(c) Ministère de la Culture et de la Communication, CNRS 


\title{
Fortifications et résidences des élites du haut Moyen Âge entre Loire et Garonne
}

\author{
Luc Bourgeois
}

\author{
Identifiant de l'opération archéologique : 204334 \\ Date de l'opération : 2008 (PC)
}

Si l'archéologie du château des XI ${ }^{\text {e}}-\mathrm{XV}{ }^{\text {e }}$ s. a connu d'importants développements, les formes de fortifications et de résidences élitaires du haut Moyen Âge ont encore peu retenu l'attention. Le projet collectif de recherche initié en 2008 entre la Loire et la Garonne a pour objectifs :

1. de dresser un inventaire systématique des sites connus par les textes et par l'archéologie ;

2. de réaliser des notices plus amples pour un certain nombre de sites.

Un inventaire sommaire comprenant 200 sites attestés entre le $\mathrm{V}{ }^{\mathrm{e}} \mathrm{s}$. et les environs de l'an mil a été réalisé (Fig. $\mathrm{n}^{\circ} 1$ : Catégories de sites par diocèse). Il illustre de fortes disparités entre diocèses, qui sont en partie liées à une conservation très diverse des sources écrites selon les secteurs.

La typologie des sites bien caractérisés est très variée puisqu'elle intègre les enceintes de cités, dont le devenir après le Bas Empire n'a guère été étudié, des fortifications de hauteur citées avant 900, qui n'ont jamais fait l'objet de travaux archéologiques d'envergure, des castra attestés au $\mathrm{X}^{\mathrm{e}} \mathrm{s}$. et quelques fortifications monastiques d'époque carolingienne (Fig. $n^{\circ} 2$ : Typologie des sites). Les habitats élitaires ouverts connaissent également une ample hiérarchie : palais carolingiens du royaume d'Aquitaine, palais ducaux et comtaux ou épiscopaux, résidences rurales qui commencent à être reconnues 
par l'archéologie préventive et nombreuses curtes signalées par les textes. En exergue, un habitat privilégié en grotte (Agris, Charente), a été relevé, plusieurs sites troglodytes

étant également implantés en Périgord.

Cette première année du projet a permis de réaliser des notices plus détaillées sur quelques uns de ces sites. La mise en défense des monastères du diocèse de Poitiers a fait l'objet d'un dossier systématique (Luc Bourgeois, Isabelle Cartron). Si la fortification de l'abbaye de Noirmoutier remonte aux années 820 et celle de Saint-Savin-sur-Gartempe peut être rapportée à la seconde moitié $\mathrm{du} \mathrm{IX}^{\mathrm{e}} \mathrm{s}$., une série de réalisations de ce type concorde avec l'affermissement du duché d'Aquitaine dans les années 930-950 (SaintHilaire et Sainte-Radegonde de Poitiers, Saint-Maixent-l'Ecole). La mise en défense des communautés de Saint-Philbert-de-Grandlieu, Saint-Jouin-de-Marnes et Charroux est envisagée à partir d'arguments morphologiques.

Les autres notices présentées concernent des sites de nature très diverse. JeanFrançois Boyer étudie trois établissements associés de Corrèze : le castrum mérovingien de Bar-le-Vieux, le castellum et la curtis carolingiens de Castellucius et de Dignac. Les premières recherches sur le vaste établissement fortifié de Champtoceaux (Maine-etLoire), attesté à partir du VI ${ }^{\mathrm{e}} \mathrm{s}$. sont présentées par Philippe Boeckler. Les récentes fouilles menées à Pouthumé (Châtellerault, Vienne) ont révélé un habitat ouvert de VII e_ $\mathrm{X}^{\mathrm{e}} \mathrm{s}$. qui s'inspire d'une villa antique sur cour (Thierry Cornec, Bernard Farago-Szekeres). L'épitaphe d'un proche des ducs d'Aquitaine du milieu du X ${ }^{\mathrm{e}} \mathrm{s}$., découverte sur ce site, fait l'objet d'une annexe (Cécile Treffort). Textes et analyse morphologique convergent pour restituer l'enceinte et le palais de Saint-Projet à Bordeaux (Frédéric Boutoulle, Ezéchiel Jean-Courret). Enfin, le castrum de Ségur et la question des sites castraux du Limousin au $\mathrm{X}^{\mathrm{e}} \mathrm{s}$. ont donné lieu à un bilan documentaire (Christian Rémy).

BOURGEOIS, Luc

\section{ANNEXES}


Fig. $n^{\circ} 1$ : Catégories de sites par diocèse

\section{Tableau I : catégories de sites par diocèse}

\begin{tabular}{|l|c|c|c|c|}
\hline Diocèse & $\begin{array}{c}\text { Sites } \\
\text { attestés }\end{array}$ & $\begin{array}{c}\text { Sites } \\
\text { à vérifier }\end{array}$ & $\begin{array}{c}\text { Site } \\
\text { rejetés }\end{array}$ & Total \\
\hline Angoulême & 15 & 1 & & 16 \\
\hline Bazas & 4 & 1 & & 5 \\
\hline Bordeaux & 10 & 3 & & 13 \\
\hline Limoges & 73 & 6 & 2 & 81 \\
\hline Périgueux & 17 & 2 & & 19 \\
\hline Poitiers & 45 & 6 & 2 & 53 \\
\hline Saintes & 11 & 2 & & 13 \\
\hline TOTAL & 175 & 21 & 4 & 200 \\
\hline
\end{tabular}

Auteur(s) : Bourgeois, Luc (SUP). Crédits : Bourgeois, Luc (2008)

Fig. $\mathrm{n}^{\circ} 2$ : Typologie des sites

Tableau II : typologie des sites

\begin{tabular}{|l|c|}
\hline Type & Nombre \\
\hline Enceinte de cité & 7 \\
\hline Castrum av. 900 & 27 \\
\hline Castrum ap. 900 & 63 \\
\hline Castrum monastique & 6 \\
\hline Palais épiscopal & 7 \\
\hline Palais royal & 6 \\
\hline Palais (autres) & 3 \\
\hline Résidence ouverte (archéologie) & 3 \\
\hline Curtis (textes) & 50 \\
\hline Habitat en grotte & 1 \\
\hline
\end{tabular}

Auteur(s) : Bourgeois, Luc (SUP). Crédits : Bourgeois, Luc (2008)

INDEX

Thèmes : abbaye, diocèse, documentation, élite, enceinte, fortification, inventaire, monastère, palais, résidence aristocratique, sources écrites, villa

Index chronologique : haut Moyen Âge, IXe siècle apr. J.-C., Ve siècle apr. J.-C., VIe siècle apr. J.C., VIIe siècle apr. J.-C., VIIIe siècle apr. J.-C., Xe siècle apr. J.-C.

operation Projet collectif de recherche (PCR)

Index géographique : Poitou-Charentes 


\section{AUTEURS}

\section{LUC BOURGEOIS}

SUP 